\title{
Prospects for world agriculture towards the near future
}

\author{
Prospecções para a agricultura mundial no futuro próximo
}

\section{Leonardo Bianco de Carvalho}

The present note is based on a publication by the Food and Agriculture Organization of the United Nations (FAO), entitled "World agriculture: towards 2015/2030" (FAO 2002). The objective is to summarize the issues pointed out for FAO on the challenges to agriculture during the next year.

The future of agriculture is dependent on the improvement of food security and sustainability (FAO 2002). In order to do this, it is necessary to analyze many contributory factors in assessing the prospects for progress towards improved food security and sustainability worldwide, according to the FAO study. One of the main challenges refers to a range of issues pertaining to the overall economic and international trading conditions, and those affecting rural poverty (FAO 2002). It affects the status and future of agricultural resources and technology. Of the many issues, FAO concluded that the development of local food production in the low-income countries with high dependence on agriculture for employment and income is the one factor that dominates all others in determining progress or failure in improving their food security.

The FAO study also predicted that the uneven path of progress is, unfortunately, likely to extend well into this century. It indicates that in spite of some significant enhancements in food security and nutrition by the year 2015, mainly resulting from increased domestic production but also from additional growth in food imports, the World Food Summit target of halving the number of undernourished persons by no later than 2015 is far from being reached, and may not be accomplished even by 2030 (FAO 2002). However, according to the study, parts of South Asia may still be in a difficult position and much of sub-Saharan Africa will probably not be significantly better off and may possibly be even worse off than at present in the absence of concerted action by all concerned. Therefore, the world must brace itself for continuing interventions to cope with the consequences of local food crises and for action to permanently remove their root causes (FAO 2002).

FAO emphasized that significant upgrading of the overall development performance of the lagging countries, with emphasis on hunger and poverty reduction, will free the world of the most pressing food insecurity problems (FAO 2002). A conclusion of the FAO study is that any progress towards this goal depends on many factors, not least among which the political will and mobilization of additional required resources; so that past experience underlines the crucial role of agriculture in the process of overall national development, particularly where a large part of the population, depends on the sector for employment and income.

On the issue of sustainability, FAO emphasized that there is an assessment of the possible extent and intensity of use of resources over the years to 2030 and concluded that pressure on resources, including those that are associated with degradation, will continue to build up albeit at a slower rate than in the past. The main pressures threatening sustainability are likely to be those emanating from rural poverty, as more and more people attempt to extract a living out of dwindling resources (FAO 2002). When these processes occur in an environment of fragile and limited resources and when the circumstances for introducing sustainable technologies and practices are not propitious, the risk grows that a vicious circle of poverty and resource degradation will set in, as FAO pointed out.

Mr. Jacques Diouf, Director-General of FAO, concluded by reiterating the importance of developing sustainable local food production and of rural development in the low-income countries; most of them depend highly on agriculture for employment and income as an important and, often, the critical component of any strategy to improve their levels

Santa Catarina State University, Lages, SC, Brazil<leonardo.carvalho@udesc.br>. 
of food security and alleviate poverty (FAO 2002). In conclusion, it is for this reason that sustainable agricultural and rural development must be given enhanced priority in all strategic framework for FAO and others organizations for food production and agriculture security and sustainability.

\section{SOURCE}

FAO - FOOD AND AGRICULTURE ORGANIZATION

OF THE UNITED NATIONS. 2002. World agriculture: towards 2015/2030. Rome: FAO. 97 p. 